\section{Depoimento Especial e a subordinação de direitos ao sistema penal: uma tríplice violação}

\author{
Special Testimony and the \\ subordination of rights to \\ the penal system: a triple \\ violation
}

\section{Juliana Christofoli Panza ${ }^{a}$ \\ (D) https://orcid.org/0000-0001-7857-1143}

Resumo: Por meio de uma pesquisa bibliográfica, este artigo introduz o debate sobre o Depoimento Especial e desvela três diferentes violações de direitos presentes em sua execução. A partir disso, firmam-se as bases necessárias para dissipar as cortinas de fumaça que envolvem o assunto, em prol da compreensão sobre a sua real serventia, revelando que, ao contrário da forma como é apresentada, a Lei n. 13.431/2017 não está centrada nos direitos das crianças e dos adolescentes.

Palavras-chave: Depoimento Especial. Lei n. 13.431/2017. Tribunal de Justiça. Sistema Penal.

Abstract: By utilizing bibliographical research, the article introduces the debate on the Special Testimony and reveals three different violations of rights in its execution. Consequently, the necessary bases are established with the objective of to clarify the topic and providing its real value, and revealing that, contrary to how it appears, Law n. 13.431/2017 is not centered on the rights of children and adolescents.

Keywords: Special Testimony. Law n. $13.431 / 2017$. Court of Justice. Penal System.

\section{Introdução}

A origem do Depoimento Especial (DE) no Brasil está relacionada à iniciativa do Dr. José Antônio Daltoé Cezar que, em sua atuação como Juiz de Direito no estado do Rio Grande do Sul, tomando como base o trabalho acadêmico da Promotora de Justiça Dra. Veleda Maria Dobke, instituiu que a escuta judicial de crianças e adolescentes (C/A), vítimas de violência sexual, passasse a ser realizada por Assistentes Sociais (AS) e Psicólogos do Juízo, sendo acompanhada pelos demais integrantes por meio de equipamento de áudio e vídeo.

A justificativa para o rompimento com o padrão até então adotado era de que, dessa maneira, se garantia mais cuidado e respeito às $C / A$, visto que as experiências nos métodos até então adotados não se mostravam adequadas com relação à forma como as vítimas eram tratadas e, principalmente, às 
perguntas que lhes eram feitas - o que as expunha a situações revitimizantes e dificultava o bom colhimento da prova testemunhal.

Nesse período, o procedimento foi denominado Depoimento Sem Dano (DSD) e a primeira audiência nesse formato ocorreu no dia 6 de maio de 2003. A partir desse momento, o projeto passou a receber grande apoio do Tribunal de Justiça do Rio Grande do Sul, o que fomentou sua divulgação e provocou os Conselhos Profissionais de Serviço Social e Psicologia a olharem para a questão.

Diante do cenário que estava se desenhando, ambos os Conselhos se manifestaram contrários ao Depoimento Sem Dano por entenderem a impertinência da inserção profissional de AS e Psicólogos, ressaltando a inexistência do vínculo entre as atribuições profissionais e a formação acadêmica com essa nova técnica de inquirição de $\mathrm{C} / \mathrm{A}$.

Os posicionamentos dos Conselhos Federais de Serviço Social e Psicologia (CFESS/CFP) foram materializados por meio das Resoluções 554/2009 e 10/2010 que proibiam tal atuação. Contudo, as resoluções foram questionadas via mandado de segurança impetrado no ano de 2011, que impediu os Conselhos de imporem penalidades aos profissionais que atuassem no DSD. Um ano depois, foi ajuizada Ação Civil Pública de autoria do Ministério Público Federal e, por meio de sentença proferida no ano de 2013, os efeitos das resoluções foram suspendidos. Após o trânsito das fases recursais, em 2020 as resoluções foram definitivamente invalidadas pela Justiça Federal.

Assim, desde esse período inicial de implantação do novo formato de inquirição, os posicionamentos contrários ao procedimento passaram a ser cada vez mais desconsiderados pelo Tribunal de Justiça (TJ) e os profissionais levados a tomar como sua essa função que foi se expandindo pelo país por meio de protocolos. Como meio efetivo para se instituir o procedimento, diversos projetos de lei (PL) passaram a ser pensados desde os primórdios dessa prática, contudo foi apenas no ano de 2015 que foi criado o PL Federal n. 3.792 que deu origem à Lei n. 13.431/2017, de autoria da deputada Maria do Rosário e outros, em parceria com o Unicef (Fundo Internacional de Emergência das Nações Unidas para a Infância) e a ChildHood.

No ano de 2018, a legislação entrou em vigor e, a partir disso, o TJSP passou a organizar cursos compulsórios para capacitar AS e Psicólogos a executarem o agora denominado Depoimento Especial. ${ }^{1}$ Daí em diante, o procedimento foi massivamente instaurado e a participação das equipes técnicas foi inserida

1 Dessa maneira, os profissionais passaram a atender ao previsto por Lei que, embora não especifique profissões, indica uma suposta especialização profissional (que foi feita por meio dessas capacitações). 
como atribuição regulamentada ${ }^{2}$ internamente no TJSP e, com as resoluções suspendidas (e posteriormente invalidadas), os profissionais passaram a exercer a função de inquiridores.

Ponto importante a se destacar aqui é o fato de que embora o procedimento de inquirição tenha sido inicialmente pensado para situações de violência sexual, a legislação ampliou o entendimento, abarcando, agora, todas as modalidades de violência contra C/A. Essa expansão prevista é problemática e denota que não houve a necessária discussão acerca das especificididades que envolvem cada tipificação de violência sofrida por $\mathrm{C} / \mathrm{A}$, visto que esse "[...] é um campo aberto e polissêmico" e que "A Lei 13.431 traz violências distintas sem nenhuma reflexão sobre isso" (Matos, 2019, n.p.).

As situações nominadas e conceituadas são diferentes pela sua natureza, pelas causas que as geram, pela forma como impactam a vida dos sujeitos singulares e coletivos e pelas formas como podem ser enfrentadas. Desse modo, ao ampliar o campo de violências a que se referem as possibilidades de realização do depoimento especial, duas questões aparecem de forma latente: a primeira é o total desconhecimento das diferenças e impactos de cada uma dessas violências na vida das crianças e adolescentes; e a

2 Portaria n. 9.796, 23 de outubro de 2019, TJSP, SGP. outra refere-se à adoção de mecanismos repressivos como método de solução prioritário [...] (Möller; Diniz, 2018, n.p.).

Essa ampliação será mais um indício do que se defenderá adiante: o DE não está a serviço de crianças e adolescentes. Assim, situado brevemente o histórico percorrido até aqui, apresentar-se-á uma perspectiva sobre três diferentes direitos que são violados na execução do DE para que, então, reúnam-se as bases necessárias para dissipar as nuvens de fumaça que envolvem o assunto em prol da compreensão de sua real serventia.

\section{Violação dos direitos de crianças e adolescentes}

Para explicar essa violação de direitos, há que se resgatar a contribuição trazida por Foucault (1988) acerca dos mecanismos de poder relacionados ao sexo e à sexualidade. ${ }^{3} \mathrm{O}$ autor aponta as mudanças históricas que ocorreram na tratativa dessa questão, pontuando períodos em que, primeiramente, constituíam-se uma total proibição e o silenciamento dos assuntos relativos ao sexo, o que posteriormente foi deslocado

3 Embora a Lei se aplique a todas as formas de violência contra $\mathrm{C} / \mathrm{A}$, como seu projeto inicial (DSD) foi formulado tendo como base a violência sexual, o artigo traz como foco essa tipificação como crime disparador tanto da construção da Lei n. 13.431/2017 quanto do uso majoritário do DE nas ações que a envolvem. 
pelo estímulo à colocação da temática em discurso.

Contudo, tal estímulo foi também empregado com finalidades de controle, tanto em prol do domínio moral religioso (pela sujeição daquilo que é colocado como pecaminoso) quanto para o domínio político do Estado (em práticas de gerenciamento e regulação do sexo visando ao controle demográfico). Assim, mesmo as formas de regulação do sexo que se assentam no discurso são regidas pela repressão/censura e, portanto, seguem relegando-o ao silenciamento.

É a partir da compreensão dessa dinâmica de poder, que tem como base a repressão e o silenciamento, que será possível refletir sobre o primeiro ponto indicativo do potencial danoso do DE: como um procedimento inserido na contraposição de se estabelecer o imperativo da fala de C/A em um contexto social de censura aos assuntos relacionados ao sexo e à sexualidade - e que, nesse caso, é ainda mais acentuado pela total negação da existência da sexualidade infantil; pelos tabus que envolvem a questão; e pela pretensão de que C/A falem sobre uma vivência de sexualidade que está descolada de seu próprio processo de desenvolvimento cognitivo e da qual seu próprio corpo foi objeto.

Posto isso é preciso pontuar, também, que a violência não é danosa apenas como fato objetivo e que, por isso, a vivência de uma situação de abuso sexual (embora, obviamente, negativa para a criança por ser uma violação à sua integridade física) não necessariamente se constituirá em um trauma. Sobre isso, Piza (2019) explica que o potencial traumático não está localizado só no acontecimento externo, mas muito mais na possibilidade que as $\mathrm{C} / \mathrm{A}$ têm de se defender psiquicamente do que há de traumático nele.

O que é apresentado por Freud (1969), nesse contexto, é que as defesas psíquicas têm papel preponderante na constituição da cena traumática, e os fatos ocorridos ganham valor secundário nesse processo. Ou seja, as experiências de violência que as C/A podem vir a vivenciar durante a infância não têm papel traumatogênico por si só, a depender das forças e dos recursos psíquicos que terão para fazer frente a essas mesmas experiências. Assim, é o caminho posterior de elaboração (ou não) dessa vivência que poderá se converter em um trauma.

Ressalta-se que não há, aqui, desconsideração acerca da seriedade do fato concreto (violência sexual cometida), mas indicação de que os desdobramentos de uma revelação de abuso, a partir das conduções às quais as C/A são submetidas, podem provocar mais danos (ao campo da subjetividade) do que o próprio fato em si. Nesse sentido, estaria o DE a serviço da elaboração dessa vivência, ou, ao contrário, seria o procedimento um potencial provocador da conversão da vivência da violência em trauma? 
$\mathrm{Na}$ engrenagem do $\mathrm{DE}$, está em jogo o par de opostos entre lembrança e esquecimento, e tanto um processo quanto o outro nem sempre é conduzido de forma adequada pelo Judiciário que se centra unicamente em produzir provas para condenar o acusado, não em ouvir a criança/adolescente respeitando a sua própria singularidade/subjetividade. Com isso, colocam-se no encargo da criança o testemunho e a lembrança arbitrária sobre os fatos - lembrança que é solicitada com o objetivo claro de fomentar o curso de uma ação penal.

Pensar o DE a partir desse prisma possibilita encará-lo como uma forma de interferência que não dá oportunidades seguras para a elaboração dessa lembrança, que é revirada em depoimento. Ao contrário, trata-se de um convite para falar sobre aquilo de que não se lembra ou que se preferiria falar em outro ambiente diferente daquele ofertado pelo $\mathrm{DE}$ - visto que, nesse cenário, há ainda a necessidade de as C/A lidarem com os motivos de seu testemunho (averiguação dos fatos) e com os efeitos provocados por sua fala (punição ou absolvição do seu suposto violador).

No âmbito do DE, a lembrança e a fala sobre a cena de violência têm, portanto, função exclusiva de denúncia e prova, sem ofertas reais de recursos que auxiliem na elaboração. Nesse sentido, o esquecimento muitas vezes é impedido pela demanda do Judiciário em solicitar que as C/A falem e relembrem a violência em seu relato-denúncia - visto como principal peça capaz de responsabilizar o agressor que os vitimou (e com quem, geralmente, nutrem vinculação afetiva). Assim, é pouco provável que, nesse contexto de imperativo da fala que orienta o procedimento, as $\mathrm{C} / \mathrm{A}$ encontrem condições para elaborar suas vivências.

Assim, a insistência do Poder Judiciário em abordar os fatos - utilizando para isso a fala e a comunicação de uma suposta lembrança com qualidade de verdade (que ganha função de material pericial) - não considera as reais possibilidades ou impossibilidades de as C/A falarem sobre a violência. Para além disso, o procedimento ainda imputa que as C/A permaneçam no mesmo ambiente que seu suposto agressor, ainda que não o vejam, e lhes faculta a responsabilidade de falar sobre um crime cometido por alguém que, geralmente, faz parte de seu ciclo de afetos (visto que a violência sexual em geral ocorre no interior das relações familiares ou comunitárias).

Nesse cenário, as C/A são colocados em uma posição em que a sua fala poderá ser o meio pelo qual alguém pertencente às suas relações afetivas será condenado à prisão. Nesse mesmo sentido, caso o acusado não seja condenado, as C/A também precisarão lidar com a deslegitimação do seu relato - que não foi devidamente credenciado pelos sujeitos envolvidos (personalizado na figura do Juiz que, simbolicamente, tem 
um peso sociocultural importante como julgador da verdade). O DE termina, então, por diminuir a chance de a criança/ adolescente reassumir a construção de sua própria narrativa.

Dessa forma, não há como se confundir o direito de serem ouvidos (previsto no artigo 100, parágrafo único, do Estatuto da Criança e do Adolescente) com a inquirição travestida de escuta, a qual essas crianças/adolescentes são submetidos no Judiciário. À vista disso, se inicialmente o DE aparenta ser uma forma de escutar o sofrimento da violência sexual contra $\mathrm{C} / \mathrm{A}$, em análises mais profundas, ele se revela como um intensificador desse mesmo sofrimento, reiterando a objetificação dos sujeitos promovida pelos dispositivos jurídicos e pela própria dinâmica de violência.

O que essas crianças/adolescentes necessitam certamente não é relatar de forma inquiridora e testemunhal o que lhes aconteceu, mas precisam de acolhimento e cuidado, o que só pode ser feito fora do campo penal e do DE, sem a carga de responsabilização que lhes é colocada no sentido de provarem a culpa daqueles que os vitimaram.

Por fim, tomando o que foi posto até aqui como horizonte de análise, entende-se que há possibilidades de considerar o DE uma medida que faz o inverso do que propõe, portanto como um procedimento que vitimiza as C/A em um segundo tempo. Diante disso, o DE está na contramão da doutrina de
Proteção Integral e especificamente dos artigos 17 e 18, bem como do inciso IV do artigo 100 do Estatuto da Criança e do Adolescente.

\section{Violação dos direitos de defesa do acusado}

O princípio que norteia o ordenamento jurídico brasileiro está previsto no artigo $5^{\circ}$, inciso LIV, da Constituição Federal de 1988, e é denominado Princípio do Devido Processo Legal. Esse princípio é sustentado pelos direitos à ampla defesa e ao contraditório: garantias de defesa legalmente previstas ao acusado. A ampla defesa diz respeito à garantia que todo acusado tem de apresentar no processo tudo que considere necessário para provar a sua verdade. Para isso, tem como base tanto a defesa técnica (representada na figura do defensor ou advogado) quanto a autodefesa.

Já o contraditório é um direito que dá concretude ao conceito de ampla defesa, pois diz respeito ao direito de acesso a todas as informações do processo e ao direito de reação e resposta imediata: que tem como dimensão importante a igualdade de oportunidades. Essa igualdade de oportunidades só é verdadeiramente estabelecida a partir de uma participação que seja efetiva e igualitária entre as partes de um processo.

É só com a garantia desses pressupostos que se tem, de fato, a constituição de uma prova judicial conforme previsto 
pela lei." Tais provas podem ser apresentadas de forma documental, material ou testemunhal, podendo ser obtidas como meio de prova: que servem diretamente ao convencimento do juiz; e meio de obtenção de prova: instrumentos usados para a obtenção da prova (Lima, 2018).

No caso do DE, tem-se, portanto, um meio de obtenção de prova, um instrumento que oferece ao Poder Judiciário mais chances de extrair das C/A a prova testemunhal necessária para o julgamento do acusado. "Apesar de a lei justificar-se na necessidade de redução dos efeitos da revitimização, a normatização acerca do procedimento de colheita do depoimento especial deixa clara a intenção do legislador de utilização de saberes 'psi' na prospecção da verdade para fins de imputação de culpa criminal" (Shimizu, 2019, p. 259).

Explicado isso, a primeira violação de direito do acusado diz respeito ao fato de que é previsto no artigo 12 , $\S 3^{\circ}$, da Lei n. 13.431/2017, que: “O profissional especializado comunicará ao juiz se verificar que a presença, na sala de audiência, do autor da violência pode prejudicar o depoimento especial ou colocar o depoente em situação de risco, caso em que, fazendo constar em termo, será autorizado o afastamento do imputado" (Brasil, 2017), permanecendo, nesse caso, apenas o seu defensor.

4 Com exceção das provas cautelares, provas não repetíveis e provas antecipadas.
Ocorre que, embora o artigo 217 do Código de Processo Penal (CPP) possibilite a retirada presencial do acusado da sala de audiência, para além de o impedimento da presença precisar estar pautado em justificativas que constem em termo (explicando os motivos da sua retirada). Fica garantido ao acusado o acompanhamento do depoimento por meio de videoconferência - exatamente para que os direitos à autodefesa, à reação imediata e à igualdade de oportunidade sejam preservados.

Entretanto, no caso do DE, está prevista na própria Lei a possibilidade de total ausência do acusado, mesmo diante do fato de o depoimento já ocorrer por videoconferência. Para complexibilizar a questão, a justificativa que acaba constando em termo é a de que o profissional especializado contraindicou sua presença (uma clara instrumentalização do trabalho do profissional em prol das necessidades jurídicas). Assim, é possível afirmar que a violação desse direito denota inconstitucionalidade na Lei n. 13.431/2017.

O segundo ponto acerca da violação de direitos do acusado diz respeito à produção de provas. No ano de 2008 , com a alteração no CPP, foi estabelecido por meio do artigo 212 que as perguntas (feitas a vítimas e testemunhas que depõem em audiência) devem ser formuladas diretamente pelos defensores/advogados e promotores. Nesse caso, atribui-se aos juízes a função de conduzir a audiência, 
podendo admitir ou não os questionamentos levantados - sempre fazendo constar em termo os motivos de algum possível veto.

Acontece que, no DE, as perguntas são feitas em bloco, podendo ser reelaboradas (para que se garanta o livre relato da criança/adolescente) ou mesmo contraindicadas pelo profissional especializado. No caso da contraindicação, cabe ao juiz decidir acerca do veto. Assim, técnicos do juízo, defesa do acusado e promotoria ficam suscetíveis às decisões exclusivas do magistrado.

Nesse caso existe, portanto, uma contraposição entre o que está estabelecido no CPP com relação à garantia de produção de provas, pois as perguntas não são feitas diretamente às vítimas/ testemunhas; não são repassadas da maneira como foram formuladas pela defesa/promotoria; e porque o veto a perguntas que, sob o ponto de vista da proteção das $\mathrm{C} / \mathrm{A}$, podem ser danosas, na perspectiva do direito e de algumas compreensões necessárias à defesa do réu, pode ser fundamental e interferir diretamente no sentenciamento do acusado. Dessa maneira há, portanto, violação do direito à produção de provas.

\section{Violação dos direitos profissionais}

No que concerne ao direito profissional, centrado aqui no Serviço Social, é necessário partir da compreensão da profissão como uma especialização do trabalho coletivo, inserida no modo de produção capitalista - com funções e valores que correspondem a esse sistema (ainda que em uma perspectiva contra-hegemônica). Assim, na divisão sociotécnica do trabalho, o Serviço Social se situa no lugar daqueles que vendem a sua força de trabalho - tendo caráter tanto interventivo quanto de produção de conhecimento, cuja atuação é pautada por um projeto profissional voltado para ideais emancipatórios que estão expressos nas normativas que regem a profissão.

Atualmente, o Serviço Social afirma, de forma hegemônica, seu compromisso com os interesses da classe trabalhadora; voltando-se à defesa dos direitos sociais, dos valores democráticos e emancipatórios; direcionando-se a partir de perspectivas de justiça, equidade e liberdade; contra as opressões de classe, raça e gênero; e com vista à superação do modelo societário vigente. Para isso, o Serviço Social tem como seu objeto de intervenção a Questão Social - produto do desenvolvimento capitalista, que é materializada em diversas expressões (como fome, pobreza, violência, desigualdade, entre outras).

Contudo, ao mesmo tempo que o compromisso profissional dos Assistentes Sociais se direciona pelos interesses das populações atendidas, ele se realiza em uma relação contraditória: visto 
que há necessidade de se responder, também, às demandas das instituições empregadoras (que, por vezes, servem à manutenção do status quo). Nesse contexto, existem diversos tensionamentos, e é a partir dessa perspectiva que será possível compreender a participação dos profissionais no DE como uma exigência que parte de uma instituição empregadora (TJ) e que é vista pela categoria profissional de forma contrária aos direitos da população atendida e, por isso, incompatível com as atribuições e o próprio projeto ético-político da profissão.

Partindo da compreensão de que a atuação de Assistentes Sociais tem como direcionamento central a garantia de direitos e tendo ficado expresso nas explicações anteriores que o DE é um procedimento violador de direitos importantes, a obrigação imposta aos profissionais em assumir essa atribuição se contrapõe tanto ao projeto ético-político quanto ao código de ética profissional, visto não existir nenhum ponto de convergência entre a formação teórico-metodológica, ético-política e técnico-operativa com a execução do procedimento.

Portanto, ao ser obrigado a assumir uma atribuição que não compõe o conjunto de suas atribuições regulamentadas, o profissional é colocado em incoerência e em desrespeito aos princípios éticos da profissão. Dessa maneira, a participação no DE viola os princípios fundamentais à "defesa intransigente dos direitos humanos" e ao "compromisso com a qualidade dos serviços prestados", bem como os artigos $2^{\circ}, 4^{\circ}$ e $8^{\circ}$ do Código de Ética Profissional de 1993 (mas não como uma questão individual do profissional que executa o DE, e sim numa perspectiva ampla, de total desvinculação entre a atividade e a própria profissão).

Assim, tendo em vista que o trabalho no $\mathrm{TJ}$ tem como norte a defesa dos direitos e a proteção de crianças e adolescentes (sendo realizado a partir do assessoramento às decisões judiciais, por meio dos estudos sociais e laudos elaborados com o sigilo previsto e com o uso de instrumentais técnicos definidos com autonomia), colocar a função de inquiridores a cargo dos Assistentes Sociais da maneira arbitrária e intransigente, como foi feito pelo TJ, descaracteriza os profissionais e os distancia das suas verdadeiras atribuições.

No processo de trabalho, é necessário que o assistente social estabeleça a articulação entre objeto, meios, atividade e finalidades, os quais se reportam, primeiro, ao projeto ético-político e teórico metodológico da profissão (conteúdos) e, secundariamente, à natureza e a determinantes institucionais. Se o poder-saber está relacionado à liberdade e à autonomia profissional, significa que ele se apresenta também "como possibilidade de escolha, de definição entre alternativas de ação". A escolha dos fundamentos que direcionam a ação se dá a 
partir de determinados interesses, com determinadas finalidades. Isto é, a escolha dos meios relaciona-se diretamente aos fins. Pergunta-se, então: quais são os fins, do ponto de vista da profissão, ao atuar em DSD? (Fávero, 2008, p. 27)

Dessa maneira, o ato de submeter Assistentes Sociais ao exercício de uma função totalmente descolada daquela que estão licenciados a desempenhar os coloca em um contexto de perda de autonomia, instrumentalização e subordinação aos juízes, violando seus direitos e dificultando, ou quase impedindo, a construção da sua verdadeira identidade profissional no TJ.

\section{Sistema penal e a centralidade do punitivismo}

Tomando como base a explicitação das três diferentes violações de direitos provocadas pelo DE, firmam-se os alicerces precisos para demonstrar que, ao contrário da forma como é apresentado, o procedimento não está a serviço dos direitos das C/A. Qual seria, então, sua funcionalidade?

Na busca pela compreensão acerca da real serventia do $\mathrm{DE}$, é preciso dar início à trajetória expositiva a partir do entendimento do Estado como um regulador/garantidor da ordem que está atrelado ao modo de produção vigente (correspondendo, majoritariamente, aos interesses daqueles que o dominam).
Para Mandel (1982, p. 333), as três principais funções do Estado capitalista são:

1. criar as condições gerais de produção que não podem ser asseguradas pelas atividades privadas dos membros da classe dominante; 2 . reprimir qualquer ameaça das classes dominadas ou de frações particulares das classes dominantes ao modo de produção corrente através do Exército, da polícia, do sistema judiciário e penitenciário; 3. integrar as classes dominadas, garantir que a ideologia da sociedade continue sendo a da classe dominante e, em consequência, que as classes exploradas aceitem sua própria exploração sem o exercício direto da repressão contra elas (porque acreditam que isso é inevitável, ou que é "dos males o menor", ou a "vontade suprema”, ou porque nem percebem a exploração).

Para cumprir esse papel, o Estado (classista, racista e patriarcal-machista) tem sua estrutura institucionalizada na divisão dos poderes legislativo, executivo e judiciário, cujas funções são distintas, porém interligadas. O Poder Judiciário, foco da reflexão, cumpre a função de resguardar a Constituição e de aplicar as leis, para regular e mediar os conflitos existentes na sociedade.

Contudo, tal como o Estado, o direito e as leis são também determinados pelo sistema e pelas relações da sociedade que os produzem. Dessa maneira, não há como se falar em um Poder Judiciário autônomo ao sistema capitalista e aos 
interesses daqueles que o dominam. ${ }^{5}$ Posto isso, o Direito Penal (originado a partir das necessidades de se institucionalizar e controlar as respostas dadas aos contratos sociais rompidos) também tomará sua forma de acordo com essa lógica.

Consequentemente, para assegurar a conservação da estrutura a qual pertence, o Direito Penal se constituiu a partir de uma centralidade em práticas de vigilância e punição que trazem as perspectivas ideológicas dominantes ao definir o que é considerado crime/ delito, bem como a quem se presumirá criminoso - materializando-se como forma de controle social direcionada a populações específicas. Nesse sentido, Shecaira (2018, p. 289) apresenta a concepção de Marx sobre o crime na sociedade capitalista, indicando que sua aplicabilidade principal:

5 As relações contraditórias - inerentes ao modo de produção - produzem, também, conquistas importantes à classe trabalhadora, às pautas identitárias e aos direitos humanos como um todo (se concretizando por meio de legislações). Contudo, essas conquistas são obtidas no interior da própria estrutura e, portanto, dentro de suas permissões (Sartori, 2010). Assim, para não se cair em uma lógica meramente garantista, tão menos sucumbir em narrativas que negam a relevância dos direitos, importa saber que: embora essas conquistas contra-hegemônicas não acarretem diretamente o rompimento com o sistema, são importantes mobilizadoras que surgem da própria estrutura e tencionam a sua lógica, merecendo o devido reconhecimento, defesa e luta por expansão como caminho possível (e não como fim) para se alcançar outra forma de sociabilidade.
[...] é a sua contribuição para uma estabilidade econômica temporária em um sistema econômico que é intrinsecamente instável. Vale dizer, Marx via o crime como uma contribuição para a estabilidade política, pela legitimação do monopólio do Estado sobre a violência, e justificativa para o controle político legal das massas. [...] Para os críticos, os atos são criminosos porque é do interesse da classe dominante assim defini-los. [...] Para os radicais, as pessoas são rotuladas criminosas porque, assim as definindo, serve-se aos interesses da classe dominante. Estes afirmam que as pessoas das classes mais baixas são rotuladas criminosas e as da burguesia não, porque o controle da burguesia sobre os meios de produção lhes dá o controle do Estado, assim como da aplicação da Lei.

Convergindo com essa perspectiva, Wacquant (2019) demonstra as decorrências do neoliberalismo ao Direito Penal e ao encarceramento em massa na sociedade norte-americana, evidenciando que, a partir do momento em que se deu o enxugamento das políticas sociais (decorrente do encerramento do Estado de bem-estar social), uma parcela específica da população foi empurrada, ainda mais, para as margens da sociedade. Assim, com o consequente aumento da desigualdade e a expansão das pressões sociais que demandavam intervenção do Estado, obteve-se como resposta um grande aumento do controle policial e penal voltado a essa 
população - e diretamente relacionado à questão racial.

Sobre isso, o autor esclarece que, historicamente, os Estados Unidos recorreram às denominadas "instituições peculiares" para definir, confinar e controlar a população negra em prol da manutenção da exploração de sua força de trabalho e da garantia de seu ostracismo social (em benefício dos interesses econômicos e sociais da população branca). Aponta, por fim, que as quatro grandes instituições peculiares a que se refere são: a escravidão, o sistema de Jim Crow, os guetos e, por último, o aparelho carcerário.

Como forma de justificar a expansão do controle policial e penal anteriormente mencionado, algumas estratégias vão sendo utilizadas pelo Estado. Wacquant (2019) defende que, entre elas, está a exploração dos tabus da sexualidade e cita diversas práticas de controle penal violadoras de direitos que foram imputadas aos delinquentes sexuais do país: um mecanismo que encontra terreno fértil para fomentar a legitimação de penas, persecuções e avanços do complexo penal e que conta com a falsa sensação de segurança que é provocada na sociedade.

Nesse mesmo sentido, Davis (2016) retrata as diferentes explicações inventadas para justificar os demasiados linchamentos que ocorriam como forma de punição à população negra por supostos delitos cometidos. Dentre as tantas justificativas criadas, chegou-se à utilização dos crimes sexuais - de onde se originou o "mito do estuprador negro".

É a partir dessa leitura (que parte da exploração do tabu da sexualidade e dos crimes sexuais como chaves que abrem as portas para a justificação de ações que subvertem o sistema de justiça e auxiliam na expansão das práticas de persecução penal) que é possível pensar o DE como uma ferramenta de inquirição que faz uso dos crimes sexuais para alcançar a aprovação necessária a seu estabelecimento legal, sem que haja uma verdadeira análise, aprofundamento e ponderação acerca dos seus desdobramentos a todos os envolvidos no procedimento.

Para isso, o DE é colocado como um mecanismo protetivo a crianças e adolescentes, necessário para o alcance da punição (reparação social pretendida) e para a retenção de um dos crimes mais abominados pela sociedade. Com isso, assume-se como plausível desconsiderar os demais direitos que se colocam em xeque na execução do procedimento, os quais permanecem ofuscados em meio a essa roupagem que se apropria, irresponsavelmente, dos discursos de proteção, enquanto, na realidade, serve unicamente ao sistema penal.

\section{Considerações finais}

O caminho apresentado revela a importância dada ao sistema penal e ao encarceramento como medidas de 
controle social, utilizadas como um dos importantes meios de manutenção e reprodução da sociedade capitalista. Em contrapartida, as legislações alicerçadas nos direitos humanos (como é o caso dos direitos de crianças e adolescentes e dos direitos de defesa dos acusados) são ganhos construídos a partir das lutas sociais por um Estado promotor de direitos e, portanto, em contraposição aos interesses dominantes.

Nesse sentido, embora haja um cenário aparente onde todos esses regramentos coexistem e são tratados de forma equânime, na prática, os direitos que expressam compromissos que divergem dos proveitos do capital são menos valorados ou até desconsiderados quando colocados em disputa com aqueles que servem à lógica de manutenção da ordem. A partir desse raciocínio e tendo como norte a explicitação dos diferentes direitos violados na execução do $\mathrm{DE}$, a conclusão sobre o procedimento é a de que ele serve, exclusivamente, ao sistema penal.

Antes do prosseguimento, faz-se necessário esclarecer que não há, nesta análise, defesa à impunidade de pessoas que cometem crimes contra crianças e adolescentes. $\mathrm{O}$ que se retrata no artigo é que, devido à função estrutural estabelecida no sistema penal (a partir da utilização do crime como grande propulsor do domínio do Estado burguês e do controle social que serve à preservação dessa ordem), a resposta por meio da penalidade (na forma de encarceramento, sobretudo) tem mais valoração e importância na sociedade e, portanto, suprime procedimentos ou regramentos que possam prejudicar sua lógica.

Também não há pretensão de se defender que a escuta judicial de crianças e adolescentes vítimas de violência volte a percorrer os caminhos trilhados anteriormente à Lei n. 13.431/2017. Pelo contrário, a leitura proposta parte da percepção de que a nova legislação é reformista e apenas mascara a violência institucional historicamente perpetrada contra essas vítimas em prol da produção de provas criminais. Para isso, esse novo formato elabora um método falsamente ancorado em preceitos humanos e protetivos - afirmado por meio da instrumentalização de profissionais (Asistentes Sociais e Psicólogos) —, mas, na verdade, prossegue revitimizando crianças e adolescentes.

Assim, a realidade sobre o $\mathrm{DE}$ é que não se tem como eixo de prospecção principal o prejuízo sofrido pela parte lesada, mas a necessidade de resposta (punição) à violação da norma fixada pelo Estado. Dessa forma, a vítima está, na verdade, em segundo plano - o que desloca o sentido de equivalência/ equiparação supostamente pretendido. Assim, a criança/adolescente serve como "pano de fundo": parte interessada no processo que figura como personificação do interesse público/coletivo da sociedade, estando presente nos trâmites somente para dar vida aos atos. Ou seja, é a norma e a comprovação da ruptura 
da norma os fatores principais dessa relação penal (Pachukanis, 1988).

Em outras palavras, no DE, assume-se como justificável violar os direitos de crianças e adolescentes, dos acusados, bem como dos profissionais, em prol da resolução de uma ação criminal que demanda provas (concentradas, sobretudo, no depoimento das vítimas) para se alcançar o sentenciamento do "criminoso" e a suposta reparação social ao crime cometido, obtida por meio da pena. Entretanto, a pena de privação de liberdade por si só não possui caráter pedagógico e transformador nem do infrator nem do contexto socioeconômico e cultural (que produz as violências) no qual esse infrator está inserido. Assim, mesmo quando há condenação, a pretensa reparação social não é verdadeiramente atingida. Trata-se, portanto, de uma relação de troca exclusivamente punitivista, e que não produz mudanças nem avanços positivos para a sociedade.

Para que realmente se avance no combate à violência contra crianças e adolescentes, é necessário que se ultrapassem as abordagens meramente criminais do fenômeno, tratando a violência como um problema social — visto que existe no domínio da cultura e, portanto, é social e histórica -, que demanda abordagem política (considerando as questões de desigualdade de geração e de gênero, as relações falocêntricas e adultocêntricas constituídas em nossa sociedade, bem como as relações entre sociedade e família - observando as formas tomadas pela família burguesa como instituição produtora de diversos modos de violência que são instituídos no nível do "privado" e da "privacidade" de maneira naturalizada), além de intervenção terapêutica e social ampliadas com vítimas, familiares e agressores (Azevedo; Guerra, 2015).

Sem que haja um olhar amplo, "sócio-psicológico-cultural" (Azevedo; Guerra, 2015), que se constitua em uma política pública adequada para intervenção junto aos denunciados por crimes (sobretudo os sexuais) e suas vítimas, as finalidades atribuídas à prisão não se cumprem verdadeiramente e direitos importantes continuarão sendo violados para que se garanta uma medida de teor simbólico (pena), que prova a ação do Estado e figura como forma de gerenciamento e gestão da insegurança social, sem que, de fato, provoque mudanças e proteja efetivamente os envolvidos.

\section{Referências}

AZEVEDO, M. A.; GUERRA, V. N. As políticas sociais e a violência doméstica contra crianças e adolescentes: um desafio recuperado em São Paulo? In: AZEVEDO, M. A.; GUERRA, V. N. (org.). Infância e violência doméstica: fronteiras do conhecimento. São Paulo: Cortez, 2015.

BRASIL. Lei n. 13.431, de 4 de abril de 2017. Estabelece o sistema de garantia de direitos da criança e do adolescente vítima ou testemunha de violência e altera a Lei n. 8.069, de 13 de julho de 1990 (Estatuto da Criança e do Adolescente). Brasília, 2017. 
DAVIS, A. Mulheres, raça e classe. Tradução: Heci Regina Candiani. São Paulo: Boitempo, 2016.

FÁVERO, E. T. Metodologia "Depoimento sem Dano" ou "Depoimento com Redução de Danos". Brasília: CFESS, jan. 2008. Parecer técnico.

FOUCAULT, M. História da sexualidade I: a vontade de saber. Rio de Janeiro: Graal, 1988.

FREUD, S. Meus pontos de vista sobre o papel desempenhado pela sexualidade na etiologia das neuroses (1906 [1905]). Rio de Janeiro: Imago, 1969. Edição Standard Brasileira das Obras Completas de Sigmund Freud, v. VII.

LIMA, R. B. de. Código de Processo Penal comentado. 3. ed. rev. e atual. Salvador: Juspodivm, 2018.

MANDEL, E. O capitalismo tardio. São Paulo: Abril Cultural, 1982.

MATOS, M. C. de. Nota técnica sobre a "escuta especializada" proposta pela Lei 13.431/2017: questões para o Serviço Social. Brasília: CFESS, 2019.

MÖLER, D.; DINIZ, T. M. R. de G. Nota técnica sobre o exercício profissional de assistentes sociais e as exigências para a execução do Depoimento Especial. Brasília: CFESS, 2018.

PACHUKANIS, E. B. A teoria geral do direito e o marxismo. Tradução: Silvio Donizete Chagas. São Paulo: Editora Acadêmica, 1988.
PIZA, L. Abuso sexual: o direito e o avesso. In: BRANDÃO, E. (org.). Psicanálise e direito: subversões do sujeito no campo jurídico. Rio de Janeiro: NAU, 2019.

SARTORI, V. B. Lukács e a crítica ontológica ao direito. São Paulo: Cortez, 2010.

SHECAIRA, S. S. Criminologia. 7. ed. rev., atual. e. ampl. São Paulo: Thomson Reuters Brasil, 2018.

SHIMIZU, B. Sobre o psicanalista inquisidor: a incompatibilidade epistemológica entre a psicanálise e a persecução penal a partir do paradigma da realidade psíquica. In: SÁ, A. A. de; ALMEIDA, J. de M.; SHECAIRA, S. S. (org.). Novas perspectivas da criminologia. Belo Horizonte: D’Plácido, 2019. p. 255-274.

WACQUANT, L. Punir os pobres: a nova gestão da miséria nos Estados Unidos [a onda punitivista]. Tradução: Sérgio Lamarão. 3. ed., rev. e ampl. Rio de Janeiro: Revan, 2007. $4^{\text {a }}$ reimpr. set. 2019.

\section{Sobre a autora}

Juliana Christofoli Panza - Mestre em Serviço Social e Políticas Sociais pela Universidade Federal de São Paulo (Unifesp), Santos/SP, Brasil, e assistente social judiciária no Tribunal de Justiça de São Paulo.

E-mail: julianapanza@hotmail.com 